\title{
КОМПЛЕКС ПРЕВЕНТИВНЫХ МЕР ПО ЗАЩИТЕ БИЗНЕСА ОТ ВРАЖДЕБНОГО ПОГЛОЩЕНИЯ
}

\begin{abstract}
Аннотация. Предметом исследования данной статьи, подготовленной по итогам изучения такой дисциплины, как «Управление системами безопасности бизнеса», является один из разделов теории слияний и поглощений в бизнесе, именуемый враждебным поглощением. Методологически автор проводит обзор научных публикаций о зарубежной и российской практике. Дается теоретический анализ основных признаков, моделей, а также возможных стратегий защиты от враждебных поглощений. Автор уделяет особое внимание российской действительности, привлекая отечественное законодательство и приводя соответствуюшие ей примеры. Впервые для анализа используются фактографические данные Redel Group. Большинство описанных стратегий рекомендуется использовать комплексно для достижения максимального результата. Пилюли, парашюты и супербольшинство лучше как можно больше афишировать, тем самым снижая вероятность будущего поглощения и увеличивая цүену акций. Защчиту активов, стратегический альянс и стратегическое приобретение следует применять только в крайних случаях. Делается заключение, что не так трагична ситуация на российском рынке слияний и поглощений, как кажется на первый взгляд. Несмотря на преобладание административного ресурса, неразвитость фондового рынка, отсутствие дружественных поглощений и коррупцию, свой бизнес можно защитить, если начать заниматься этим вопросом заранее.
\end{abstract}

Ключевые слова: слияния, конгломерат, враждебные поглощения, акция, актив, ресурс, двухуровневое предложение, Российская Федерация, бельй рыцарь, ядовитые пилюли.

\section{Введение}

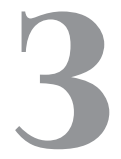
а прошедшее десятилетие невероятной удачей стало: включить телевизор, радио, открыть газету и не наткнуться там, на новость о готовящейся крупной сделке слияния или чаще поглощения. Если же перейти во всемирно известный поисковый сервис, то Googleвыдаст вам более 63 миллионов совпадений по запросу «takeover», причем примерно на девятой ссылке можно заметить новость об ОАО «Уралкалий» и его владельце Сулеймане Керимове. Еще интереснее дела обстоят с рекламой - зачастую можно найти не- приметные скромные объявления по типу «Покупаю акции, дорого».

Таким образом, слияния и поглощения превращаются в довольно актуальный международный вопрос, а говоря о российской экономике - и вовсе являются одной из главных тенденций. В качестве доказательства последнего утвержденияприведем данные аналитического агентства RedealGroup ${ }^{1}$ за прошедшие 10 лет.Цифры говорят о том, что российский рынок слияний и погло-

\footnotetext{
${ }^{1}$ Информация о рынке слияний и поглощений, по данным RedealGroup. Материалы сайта http://old.mergers. $\mathrm{ru} / \mathrm{rusrinok} /$
} 
щений показал более чем четырехкратный рост в стоимостном выражении (было 18,05 млрд. долл.- стало 79,32 млрд. долл.), при доле в $6,5 \%$ от ВВП. Представленные данные закономерны, так как слияния и поглощения служат эффективной стратегией развития компании и альтернативой более медленному органическому росту. В условиях высокой конкуренции именно слияния и поглощения ведут к увеличению выручки, доли рынка, а также открывают доступ ко многим новым технологиям.

Тем не менее, основной причиной популярности вышеописанной стратегииявляется как быстрое развитие российской экономики, так и несовершенство законодательства, а также связанных с ним враждебных поглощений, о которых и пойдет речь в настоящей статье.

\section{Основные понятия}

\section{Базовые определения}

Прежде чем непосредственно разбирать российскую специфику враждебных поглощений, методы корпоративного захвата и разрабатывать комплекс защиты, было бы полезно определить базовые термины, их признаки и отличия друг от друга.Для этого обратимся к книге Патрика Гохана «Слияния, поглощения и реструктуризация компании»1 :

Слиянием (merger) называют соединение предприятий, где две и более компании объединяются для образования совершенно новой компании $(\mathrm{A}+\mathrm{B}=\mathrm{C})$. Сделка обычно проводится по взаимному согласию, размер ее участников примерно одинаков, в СМИ упоминается со средней регулярностью.По типам слияния делятся на:

- Горизонтальные. Таким слиянием считается объединение двух и более прямых

\footnotetext{
${ }^{1}$ Патрик Гохан. Слияние, поглощение и реструктуриза-
} ция компании.- Москва.: Альпина Бизнес Букс, 2010 конкурентов. В результате происходит монополизация рынка, которая впоследствии ограничивается государством.

- Вертикальные подразумевают консолидацию компаний, находящихся в отношениях покупателя-продавца или поставщика-продавца. Данная стратегия тоже ведет к увеличению рыночной власти. Например, слившийся поставщик оказался крупнее остальных - следовательно, не интегрированные продавцы станут обращаться к нему чаще, а значит, у него появится возможность осуществлять ценовую дискриминацию.

- Конгломератные представляют оставшиеся слияния, не попавшие в первый или второй тип. То есть сделку заключают фирмы с разными стратегиями, товарами и услугами, ставя целью диверсификацию деятельности. Классический пример конгломерата -GeneralElectric, которая успешно развивается в страховой области, радиовещании и даже производстве медицинского оборудования.

Поглощение (acquisitionortakeover) процесс, в котором одна компания пытается установить контроль над другой $(\mathrm{A}+\mathrm{B}=\mathrm{A})$, посредством выдвижения на фондовом рынке тендерного предложения на ее акции (часто это подразумевает скупку 50\% и одной голосующей акции по определенной, нерыночной цене). Сделка проходит без согласия компании-цели, поглощающий участник значительно больше поглощаемого, вСМИ данная тема значительно популярнее, так как это один из инструментов влияния на стоимость акций. По типам выделяют те же горизонтальные, вертикальные и конгломератные поглощения. Результат, в целом, похож на слияния: повышается эффективность использования ресурсов, однако размещены эти ресурсы оказываются в руках меньшего числа фирм. 
Тут невольно возникает вопрос: по какой причине следует выделять именно враждебные поглощуения (hostiletakeovers), если обычные уже носят не особо дружественный характер? Ответ зависит от реакции в лице управляющих и акционеров компании-цели, от используемых методов поглощения и от общественного отношения к сделке 1 . Ведь поглощение может пройти таким образом, что часть бывших управляющих останется работать в компании, акционеры продадут акции по выгодным и высоким ценам, а фирма сократит текущие затраты по производству и сбыту продукции, начнет выпускать новые виды товаров и увеличит свою рыночную долю, причем законные рамки будут соблюдены.Поэтому похожие дружественные поглощения несложно спутать со слияниями.

Тем не менее, у вышеописанного развития событий небольшая вероятность, потому что в российских условиях цели чаще ограничиваются захватом прибыльных активов, а не их дальнейшим развитием, следовательно, наши поглощения обычно уже подразумевают конфликт и дальнейшую борьбу.

Отличительные черты российского рынка слияний и поглощуений

Мы уже упомянули в нескольких словах некоторые мотивы и тенденции российского рынка слияний и поглощений. Между тем, выбранная тема требует от нас уделять особое внимание деталям, чем мы и займемся, обратившись к статье И.Я. Новиковой и Л.И. Зухуровой ${ }^{2}$, где обозначены следующие отечественные особенности:

\footnotetext{
${ }^{1}$ Schwert W. Hostility in Takeovers: In the Eyes of the Beholder? // Journal of finance.- 2000

2 Зухурова Л., Новикова И. Слияния и поглощения в России. // ЭКО.—2007.— N6
}

- Государство и административный ресурс играют огромные роли в осуществлении сделок.

- Значительная доля сделок относится к национализации приватизированных до этого компаний.

- Отсутствие как таковых дружественных поглощений, при фактическом захвате фирмы, используя процедуры банкротства и судебные иски.

- Основные рыночные игроки - компании из добывающих отраслей.

- Большинство крупных сделок сопровождается долговым финансированием, при осуществлении сделок мелких фирм за их собственный счет.

- Расчет по сделкам в денежной форме.

Именно вышеперечисленные признаки (первые четыре строго) являются ответами на вопрос: почему множество корпоративных конфликтов, охвативших ведущие отрасли экономики (снова вспомним ОАО «Уралкалий»), регулируется исключительно с применением уголовно-правового ресурса. Пятый признак объясняет концентрацию капитала в крупных предприятиях ималую конкурентоспособность мелких фирм. Шестой же - говорит о том, что выкуп активов для российских компаний проще, чем реорганизация сливающихся участников. Причина предположительно: предприятиям сложно договориться о том, кто бизнес продает, а кто покупает, ведь продажа считается, по сути, проигрышем конкуренту.

Углубляясь в признаки непосредственноотечественных враждебных поглощений ${ }^{3}$, мы получим классификацию из четырех групп. Первая группаотвечает за причины данного вида поглощений, состоящие в реакции

\footnotetext{
${ }^{3}$ Пирогов А. Особенности слияний и поглощений российских компаний. // Управление компанией.-2002.N5
} 
на налоговое бремя, плохую защищенность прав собственников и последствиях приватизации. Вторая группа особенностей поясняет, что фондовый рынок в нашей стране мало затронут операциями слияний и поглощений, таким образом, цена акций на вторичном рынке тоже не является фактором, препятствующему враждебному поглощению. Третья группа подчеркивает специфическую структуру собственности: предпочтительность неформального контроля сделок, непрозрачная организационная структура, мнение миноритарных акционеров поглощаемой компании мало кого волнует, сложное законодательное регулирование групп компаний, находящихся в разных регионах. Четвертая группа знакомит нас с типичными формами враждебных поглощений, где отсутствуют сделки равноправных слияний и преобладают долговые схемы.

«Лакомой добычей» для враждебного поглощения предприятие становится по нескольким важным причинам. Во-первых, недооцененность акций компании - цели. Вовторых, наличие высоколиквидных активов и избыточных средств (тот же страховой или пенсионный фонд). В-третьих, если компания-мишень обладает множеством дочерних обществ, ощутимо не затрагивающих общие денежные потоки, то целью «поглотителя» станет как раз будущая продажа данных дочерних обществ.

\section{Основные методы враждебного поглощения в РФ}

Несмотря на то, что рынок слияний и поглощений в Российской Федерацииимеет большие темпы роста, в литературных источниках довольно трудно найти единую классификацию именно атак, а не способов защиты. На мой взгляд, это обосновано тем, что наиболее распространённыетипы враждебных поглощений с привлечением административного ресурса и разорением компании многим давно известны, а наиболее эффективные и интересные способы нет нужды освещать в публикациях, иначе они быстро перестанут такими являться. Между тем, А. Радыгин ${ }^{1}$ классифицирует методы враждебных поглощений в России на шесть групп, мы проанализируем пять, объединив банкротство и трансформацию долгов, ибо эти способы сбалансированно дополняют друг друга:

\section{Приобретение пакетов акций на вто-} ричном рынке. Самая распространенная схема включает в себя выбор жертвы, проведение массированной компании в СМИ по ее дискредитации, с целью снижения рыночной стоимости, параллельно с этим скупку порядка $30 \%$ акций на вторичном рынке и внезапную смену генерального директора. Последний шаг - приобретение оставшихся 21\% (или сколько потребуется) акций уже по определенной цене у официально разваливающего предприятия. Отметим, что в описанной схеме применяется метод двухуровневого предложения: сначала акции покупаются на вторичном рынке по более высокой цене, потом остальные ценные бумаги докупаются по сниженной. Переход от одного уровня предложения к другому сопровождается российской спецификой, включающей занимательную и разнообразную программу мероприятий (арест действующего генерального директора налоговой полицией, «внеочередное» собрание акционеров, без половины акционеров, множество неожиданных проверок государственными службами). В качестве примера может послужить нефтяная промышленность, где не так давно ныне «Газпром нефть» (ранее ОАО «Сибнефть»)

\footnotetext{
${ }^{1}$ Радыгин А. Слияния и поглощения в корпоративном секторе (основные подходы и задачи регулирования). // Вопросы экономики.-2002.- N12
} 


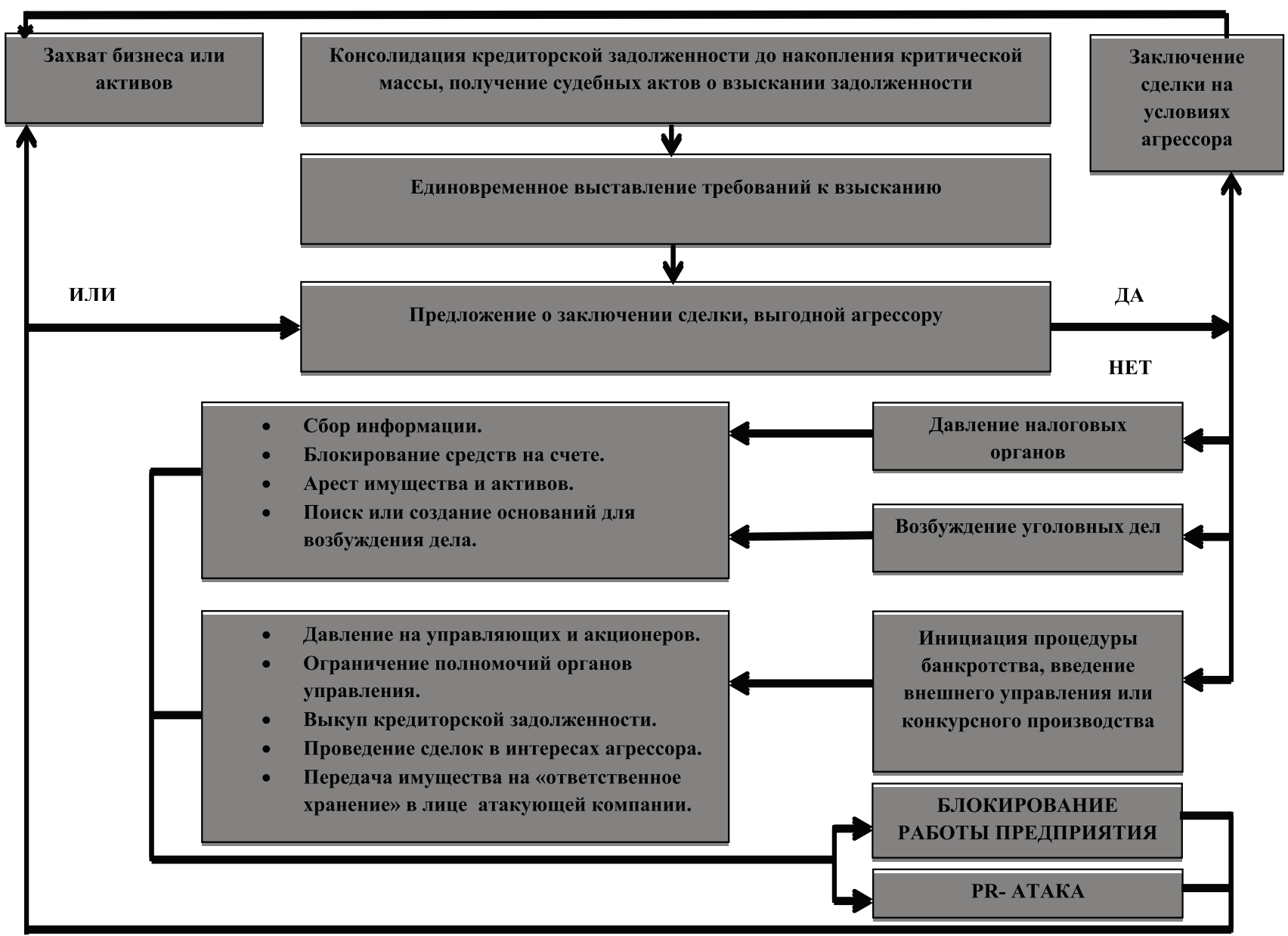

Рисунок 1. Подробная схема враждебного поглощения с помощью долгов компании

пыталась поглотить ОАО «Славнефть», начав со скупки 11\% акций на вторичном рынке.

Захват контроля с помощью банкротства компании, а такәсе использование долгов компании-мишени в своих целях. Здесь существуют два способа: действительно обанкротить компанию и потом дешево купить, или же подстроить банкротство, а потом воспользоваться законодательством. Второй метод удобнее, не так дорог, как первый и формально законен. Важным в такой стратегии служит операция по выкупу достаточного долга (в соответствии с законом «О банкротстве» ${ }^{1}$ достаточно

\footnotetext{
${ }^{1}$ Федеральный закон от 26 октября 2002 года, N 127- Ф3
} О несостоятельности (банкротстве) чуть более трехсот минимальных зарплат) у кредитора компании-мишени. После чего нападающая компания на три месяца исчезает, а затем обращается в суд с возбуждением дела о банкротстве. Во время судебного разбирательства для достижения максимального эффекта рекомендуется начать одновременно применять уже разобранную первую схему по приобретению акций на вторичном рынке. При успешной реализации такой стратегии, у кредиторов (нападающей компании) появляется право установить свой порядок продажи активов должника (компании цели). Наглядно ознакомиться со всей совокупностью шагов при данном враждебном поглощении можно на схеме (Рисунок 1). 
Привлечение "әсертвы" в холдинг или другие группы через административные cредства. Механизм данной стратегии внешне похож на процесс горизонтального слияния, и вполне может стать им внутренне, при невероятном условии, что стороны примерно одинаковы по размерам и договорятся без корпоративного конфликта. Однако нам нужно рассмотреть именно неблагоприятное развитие событий. Допустим, крупный холдинг намеревается приобрести компанию, осуществляющую деятельность на том же рынке, но ее акционеры не разделяют стремление холдинга, а менеджмент отказывается рассматривать возможность добровольного слияния. Тогда для достижения своей цели холдингу приходится применять множество экономических методов воздействия на компанию: резкое снижение цен, перехват имеющихся заказов, особые договоренности с крупными поставщиками. В итоге «жертва» постепенно сдается, ибо не может вести длительную ценовую войну. В качестве отличного примера годится агрессивная ценовая политика X5 RetailGroup, поглотившей такие крупные торговые сети, как «Копейка» и «Остров» за последние два года.

Подделка документов и фальсифицирование судебных решений. Чаще других подделывают печати и подписи нотариуса на документах о государственной регистрации изменений, договора купли-продажи-аренды имущества компании-цели, документы, позволяющие совершать сделки с ценными бумагами. С инициированием «правильных» судебных решений все бывает намного интереснее: постановления, которые были изданы несуществующими судами, не зарегистрированные нужным образомили их подписал судья, неосведомленный об этом. В общем, такой способ враждебного поглощения предоставляет агрессорам творческую свободу, кроме того, он несильно трудозатратен. Таким образом несколько лет назад, на основании поддельных документов о судебном решении, всего трое граждан пыталось осуществить рейдерский захват ООО «Таганрогский пивоваренный завод» - удалось, но впоследствии они были задержаны сотрудниками полиции по ст. 159 УК РФ.

Приватизационные сделки при помощи государственных пакетов акций. По сути, здесь идет речь не о скупке контрольного пакета акций, а об установлении строгого контроля над лицом, обладающим таким пакетом. Мотива тут два: акции государственного предприятия можно приобрести только в момент приватизации, и обанкротить такую компанию тоже не получится (ведь мало кто решится бросать вызов федеральным или региональным властям). Метод заключается в подкупе одного или нескольких чиновников, которые представляют государственные интересы на собраниях акционеров (удобнее всего чиновника Министерства имущественных отношений). При осуществлении приватизации такая неформальная связь предоставит компании - агрессору гигантское преимущество в борьбе за акции компании - цели. Недостатком метода считается его зависимость от того самого лица, представляющего интересы государства, следовательно, отсутствие четких гарантийтого, что чиновника не перекупит другая компания -агрессор.

\section{Стратегии защиты от враждебных поглощений}

Проанализировав основные угрозы, которые ожидают компании - мишени, самое время перейти разработке стратегий, которые позволят избежать поглощения бизнеса. Обзор литературы по теме выявил, что защитные меры подразделяются по двум категориям: превентивные и оперативные. 
Превентивные меры используются непосредственно перед процессом враждебного поглощения и подразумевают проектирование и применение комплекса мер, создающих правовые и экономические преграды на пути компании - агрессора. Оперативные же включают экстренный план спасения, когда вас уже вовсю поглощают (например, поступило тендерное предложение). Очевидно самыйдейственныйспособ защиты будет комбинировать как превентивные, так и оперативные меры. Если же пытаться их сравнивать, то на, мой взгляд, превентивные меры намного результативнее, снижают общую вероятность, превращения компании когда-либо в мишень для поглощения, а также ведут к меньшим затратам (то есть, лучше не заболевать, чем потом эффективно лечиться). На них мы и остановимся в данной статье, а поможет нам статья Е. Демидовой «Враждебные поглощения и защита от них в условиях корпоративного рынка России» ${ }^{1}$.

Супербольиинство. Самый распространенный и простой метод обороны активов от компании агрессора. Заключается в том, что в устав компании вносится обязательное условие: для решения о поглощении или смене руководства нужно собрать 80-90\% голосующих акций. Данная мера хорошо справляется с балансировкой интересов менеджеров и акционеров, кроме того, повышает сплоченность. Вдобавок, такая стратегия повышает цену акций, ибо показывает, что предприятию важно мнение почти всех акционеров. С другой стороны, супербольшинство увеличивает издержки на сбор и коррадиацию акционеров. Помимо этого, мера дает лишь временную передышку перед тем, как компания-агрессор превратится

\footnotetext{
${ }^{1}$ Демидова Е. Враждебные поглощения и защита от них в условиях корпоративного рынка России. // Вопросы экономики.-2007.— N4
}

в мажоритарного акционера и подаст в суд, в надежде изменить устав. Большинство российских компаний используют стратегию супербольшинства, по умолчанию (например, ОАО «Вымпелком» имеет порог в 80\%).

Заключение стратегчческого альянса или поиск «белого рыцаря». Порядок действий компании-цели в данном случае сводится к созданию альянса между двумя и более заинтересованными лицами. В идеале, это, конечно, слияние, но может быть и дружественное поглощение. Результатом является холдинг компаний, на которого сложно воздействовать экономически и который сам обладает достаточными ресурсами для проведения контратаки. В стратегии присутствует ощутимый риск - участник альянса способен превратиться в «серого рыцаря» и, пользуясь инсайдерской информацией, самостоятельно провести враждебное поглощение бывших коллег. Кроме того, объединение в группу компаний довольно комплексный процесс, ведущий за собой переорганизацию производства и сбыта, разработку нового брэнда и так далее.

\section{Золотые, серебряные и оловянные па-} paшюты. Эти развернутые метафоры обозначают специальные соглашения с сотрудниками о выплате им особой компенсации, в случае смены руководства компании-цели. Золотой цвет относится к топ-менеджменту, серебряный - подчеркивает менеджеров среднего звена, а оловянным - выделяются остальные сотрудники. Размер компенсации, как правило, зависит от сословия и в среднем составляет 3-4 годовые зарплаты. Данная защитная мера удорожает враждебное поглощение, снижает его вероятностьи незначительно повышает стоимость акций, так как показывает, что компания-цель настроена на упорное сражение. Недостаток стратегии обнаруживается в асимметрии информации, ведь топ-менеджмент знает о предприятии 
все и способен проявить оппортунистическое поведение и договориться с «поглотителем», чтобы скорее заполучить свой парашют.

Защита и перераспределение активов. Идеальной организационной структурой является та, что лишает компанию-агрессора доступа к ликвидным активам, после успешного поглощения. Ведь битва идет не за акции, а за возможность получать дивиденды от этих акций или управлять высоко прибыльной собственностью. Способ обороны - перевод активов третье стороне, либо обмен равными активами так, что балансы сторон не ухудшаются. Однако это замечательный метод только в теории, на практике возможна утрата перечисленных активов, а затем и судебный иск от собственных миноритариев - таким образом, вы еще и поможете «поглотителю». Существует и альтернативный, правда тоже рискованный, вариант этой стратегии - реструктуризация пассивов через увеличение задолженности. Применять защиту активов стоит только в случае наличии доверенного партнера, множества гарантий и полной осведомленности миноритариев.Ярким успешным примером реализации подобной стратегии служит ЮКОС, чьи акции находились во владении восьми трастов.

Ядовитые пилюли. Простой и эффективный способ обезопасить собственный бизнес, заключающийся в том, что при изменении структуры собственности акционерыполучают возможность приобретать ценные бумаги своего бывшего предприятия по бросовым ценам. Пилюли делятся на пять видов: подлинная ядовитая пилюля, опцион на покупку, замыкающий опцион, план обратной связи иплан голосования. Важное преимущество стратегии - небольшие постоянные расходы.Существенная проблема такой стратегии - отечественные законодательные ограничения: разница в ценах размещения ценных бумаг акционерам с преимущественным правом приобретения и другим лицам строго лимитирована. Помимо этого, российское предприятие не вправе выпускать целую совокупность классов обычно венных акций с разными правами голосования.

Стратегическое приобретение. Ультимативная, дорогая и непредсказуемая тактика, но действенная. В качестве удачного примера можно привести покупку (или враждебное поглощение, кто знает) ОАО «Норильский никель»контрольного пакета акций $3 \mathrm{AO}$ «Единый регистратор».

Большинство описанных выше стратегий рекомендуется использовать комплексно для достижения максимального результата. Пилюли, парашюты и супербольшинство лучше как можно больше афишировать, тем самым снижая вероятность будущего поглощения и увеличивая цену акций. Защуиту активов, стратегический альянс и стратегическое приобретениеследует применять только в крайних случаях.

\section{Заключение}

Подводя итог работе, хочется сказать, что не так трагична ситуация на российском рынке слияний и поглощений, как кажется на первый взгляд. Несмотря на преобладание административного ресурса, неразвитость фондового рынка, отсутствие дружественных поглощений и коррупцию, свой бизнес можно защитить, если начать заниматься этим вопросом заранее. Следует применять такие мощные и дешевые средства, как ядовитые пилюли, поскольку они помогут установить справедливую цену на акции, и не забывать про супербольшинство, способное дать время подумать, а не спасатьсяпри осуществлении враждебного поглощения.

Что касается тенденций рынка, то и здесь постепенно ситуация приближается к европей- 
ским коллегам.Например, за несколько месяцев до написания этой статьи Минэкономразвития подготовило проект о внесении поправок в закон «Об акционерных обществах», что должно упростить способы защиты. Следующая за- дача — регулирование рынка таким образом, чтобы осуществлять слияния было выгоднее, чем враждебные поглощения. По моему, в этом и есть та волшебная «пилюля», которая привлечет к нам западных инвесторов.

\section{Библиография}

1. Информация о рынке слияний и поглощений, по данным Redeal Group. Материалы сайта http://old.mergers.ru/rusrinok/;

2. Патрик Гохан. Слияние, поглощение и реструктуризация компании.- Москва.: Альпина Бизнес Букс, 2010;

3. Schwert W. Hostility in Takeovers: In the Eyes of the Beholder? // Journal of finance.— 2000;

4. Зухурова Л., Новикова И. Слияния и поглощения в России. // ЭКО.—2007.— N6;

5. Пирогов А. Особенности слияний и поглощений российских компаний. // Управление компанией.-2002.- N5;

6. Радыгин А. Слияния и поглощения в корпоративном секторе (основные подходы и задачи регулирования). // Вопросы экономики.-2002.- N12;

7. Демидова Е. Враждебные поглощения и защита от них в условиях корпоративного рынка России. // Вопросы экономики.-2007.- N4;

8. Царев С. А. Признаки недружественного поглощения - рейдерства // Успехи современного естествознания.-2012.- N4;

9. Рудык Н. Б. Методы защиты от враждебного поглощения: Учеб. практич. Пособие.- М.: дело, 2006.

\section{References (transliterated)}

1. Informatsiya o rynke sliyanii i pogloshchenii, po dannym Redeal Group. Materialy saita http:// old.mergers.ru/rusrinok/;

2. Patrik Gokhan. Sliyanie, pogloshchenie i restrukturizatsiya kompanii.- Moskva.: Al'pina Biznes Buks, 2010;

3. Schwert W. Hostility in Takeovers: In the Eyes of the Beholder? // Journal of finance.— 2000;

4. Zukhurova L., Novikova I. Sliyaniya i pogloshcheniya v Rossii. // EKO.—2007.— N6;

5. Pirogov A. Osobennosti sliyanii i pogloshchenii rossiiskikh kompanii. // Upravlenie kompaniei.-2002.- N5;

6. Radygin A. Sliyaniya i pogloshcheniya v korporativnom sektore (osnovnye podkhody i zadachi regulirovaniya). // Voprosy ekonomiki._-2002.— N12;

7. Demidova E. Vrazhdebnye pogloshcheniya i zashchita ot nikh v usloviyakh korporativnogo rynka Rossii. // Voprosy ekonomiki._2007._- N4;

8. Tsarev S. A. Priznaki nedruzhestvennogo pogloshcheniya — reiderstva // Uspekhi sovremennogo estestvoznaniya.-2012.- N4;

9. Rudyk N. B. Metody zashchity ot vrazhdebnogo pogloshcheniya: Ucheb. praktich. Posobie.M.: delo, 2006. 